\title{
Effects of chronotype and sleep duration on life quality and psychopathology in childhood obesity
}

Wpływ chronotypu i czasu snu na jakość życia i psychopatologię w otyłości u dzieci

\author{
${ }^{1} \mathrm{Ibrahim} \mathrm{S.} \mathrm{Esin,}{ }^{1}$ Onur B. Dursun, ${ }^{1}$ Esen Y. Demirdogen, ${ }^{1}$ Esra O. Asıkhasanoglu, \\ ${ }^{1}$ Semiha C. Aslan, ${ }^{2}$ Kezban Ozturk, ${ }^{3}$ Atilla Cayir
}

${ }^{1}$ Child and Adolescent Psychiatry, Ataturk University, Turkey

2Paediatrics, Derince Regional Training and Research Hospital, Turkey

${ }^{3}$ Paediatric Endocrinology, Erzurum Regional Training and Research Hospital, Turkey

\begin{abstract}
Introduction: Childhood obesity is associated with various levels of deterioration in the quality of life and many serious medical conditions such as psychiatric problems.

Aim of the study: The objectives of this study are to investigate whether a difference in terms of chronotype among obese and nonobese children and adolescents, and restricted sleep duration, is associated with obesity and whether chronotype and sleep duration in children and adolescents with obesity are associated with quality of life and comorbid psychiatric disorders.

Material and methods: Forty-two participants diagnosed with childhood obesity were included in the study as the study group, and thirty-five participants without childhood obesity were included as the control group. Participants and their parents completed the Questionnaire for Measuring Health-Related Quality of Life in Children and Adolescents, the Development and Well-Being Assessment, and the Childhood Chronotype Questionnaire. The duration of sleep of the participants was also provided by the parent's reporting within the scope of the study.

Results: Sleep duration was an independent risk factor for becoming obese and had a significant effect on the number of comorbid psychiatric disorders independently of the morning-evening scale score.

Conclusions: Unlike the chronotype, this study provided important evidence that sleep duration was associated with the development of obesity and the quantity of comorbid psychiatric disorders.
\end{abstract}

Key words:

psychopathology, sleep duration, life quality, childhood obesity, chronotype. 


\section{Introduction}

Childhood obesity $(\mathrm{CO})$ is one of the most serious public health challenges in the world, and the prevalence of CO has increased enormously in recent years [1, 2]. In a recent study, the prevalence of obesity among children was found to be 7.1\% [3]. A national study from Turkey revealed that among children aged $7-12$ years, $9.7 \%$ of both boys and girls were accounted as obese [4]. In parallel with the increasing prevalence of obesity in childhood, the number of comorbidities associated with obesity is increasing and the medical spending on obesity is gradually rising $[5,6]$. Psychiatric disorders are among the major comorbidities of $\mathrm{CO}$, and available data suggest that obesity is also related to numerous psychiatric disorders and psychiatric symptoms in children and adolescents $[7,8]$.

Obesity is affected by both genetic and environmental factors, and in the context of environmental factors, recent research has increasingly focused on lifestyle and chronotype [9]. One of the important factors of lifestyle is the sleep characteristics of the person. It has been shown that irregularities in lifestyles such as sleep disturbances (going to bed too late and short sleep duration) are strongly associated with $\mathrm{CO}$ $[10,11]$. According to previous studies, irregular sleep habits are not only predisposed to increased risk of obesity but are also considered potential risk factors for developing psychopathology. In addition, sleep disturbance, including short sleep duration, also has negative effects on cognitive functions (learning and memory problems), attention, mood (irritability, poor affect regulation), and behaviour (impulsive behaviour) regulation $[12,13]$.

Most studies report that secretion of obesity-related hormones and eating behaviours are affected by circadian rhythms [14-16]. Chronotype can be defined as the time of day in which individuals are "at their best". Some people, known as "larks", achieve their maximum physical and mental capacity early in the morning and become tired early in the evening. In contrast, "owls" reach their best capacity in the late afternoon and evening, and therefore they work till late night and have difficulty getting up early in the morning $[17,18]$. Most studies conducted on this subject have shown profound interactions between chronotype and obesity - the chronotype may be the intersection point of obesity and psychopathology, and they have shown that owls carry greater risk for both diseases $[19,20]$. However, the generalisability of these data is low because they were mostly obtained from adult literature and there are only a few studies on children and adolescents.

Little is known about the effects of chronotype and sleep duration on quality of life and psychopathology in childhood obesity. The first aim of this study was to investigate whether a difference in terms of chronotype among obese and nonobese children and adolescents and restricted sleep duration are associated with obesity in this age group. The secondary aim was to evaluate whether chronotype and sleep duration in children and adolescents with obesity are associated with quality of life and comorbid psychopathology.

\section{Material and methods}

\section{Sampling}

The study was conducted in the Departments of Child and Adolescent Psychiatry and Paediatric Endocrinology. Fortytwo children and adolescents, who were diagnosed with $\mathrm{CO}$ according to the definitions of the International Obesity Task Force, were included as the study group [21]. Thirty-five children and adolescents, who had normal weight, were included as the control group. Both groups were matched for gender and age. To rule out the effects of the confounders, individuals who used any medication known to affect sleep, had any chronic disease, or were had any physical and/or intellectual disability, were excluded in both groups.

Within the scope of the study, all parents were informed about the study, and written consent was obtained from all parents. Ethical approval was granted from the Ethics Committee of the Medical Faculty.

\section{Instruments}

Development and well-being assessment

The Development and Well-Being Assessment (DAWBA) was used for diagnosing Psychiatric Disorders [22]. DAWBA combines closed- and open-ended questions about common child psychiatric disorders and their impact. The instrument's validity and reliability in Turkish was assesed by Dursun et al. [23]. The last author, who is a child psychiatrist and a DAWBA rater, performed the diagnoses.

Subthreshold psychiatric disorder is defined as an intermediate level between psychopathology and a healthy state [24]. We used either with an insufficient number of symptoms for diagnoses but with significant impairments, or with an adequate number of symptoms for diagnoses but with insignificant impairments, as diagnostic criteria for subthreshold psychiatric disorder.

\section{Childhood Chronotype Questionnaire}

The Childhood Chronotype Questionnaire (CCTQ) is a parent-reported questionnaire for assessment of individual chronotypes of children and adolescents [25]. The scores, obtained from CCTQ, are used to classify individuals as morning type, intermediate type, and evening type (scores of $\leq 23,24-32$, and $\geq 33$, respectively). The validity and reliability of the CCTQ in Turkish was carried out by Dursun et al. [26].

\section{The Health-Related Quality of Life Questionnaire}

We used KINDL, which is a tool for evaluating health-related quality of life in children and adolescents with and without any disease. The questionnaire has three versions; Kiddy-KINDL (age 4-7 years), Kid-KINDL (8-12 years), and Kiddo-KINDL (13-16 years) [27]. KINDL examines psychological well-being social relationships, physical functions, and everyday life activities through 24 questions. The results are collected in six domains: physical health, emotional well-being, self-esteem, social functioning, family functioning, and school functioning. The total score ranges from 0 to 100 ; higher scores indicate 
better quality of life. KINDL's validity and reliability in Turkish was assessed by Eser et al. [28].

\section{Statistical analysis}

Statistical analyses were performed using Statistical Package for Social Sciences (SPSS) Statistics 20.0 program. All data were reported as the mean $\pm S D$, and we used the Kolmogorov-Smirnov test to analyse the normality of distribution. Depending on the data distribution, the Mann-Whitney $U$ test or the Student's t-test were used among the groups. Group differences were estimated by using the Pearson's chi-square test and Fischer's exact test for categorical variables. The relationships between quantitative normal variables were studied by linear correlation analysis (Pearson's $r$ ), whereas Spearman's rho was used for non-normally distributed variables. The statistical significance level was accepted as $p<0.05$.

\section{Results}

The study included a total of 77 children and adolescents as participants. Forty-two participants (20 males and 22 females) were included in the study group with a mean age was $11.5 \pm 2.4$ years. Thirty-five participants (20 males and 15 females) were included in the control group, with a mean age of $10.4 \pm 2.9$ years.

In the study group, the mean score of the morningnesseveningness scale was $28.1 \pm 5$, and the most common type of chronotype was intermediate. The control group's mean score of the morningness-eveningness scale was $28.4 \pm 4.5$, similar to the study group, in which the most common type of chronotype was intermediate. In the study group, $17.5 \%(n=7)$ of

Table I. The Health-Related Quality of Life Scores of the study and control groups

\begin{tabular}{llll}
\hline & $\begin{array}{l}\text { Study } \\
\text { group } \\
(n=42)\end{array}$ & $\begin{array}{l}\text { Control } \\
\text { group } \\
(n=35)\end{array}$ & p value \\
\hline Total life quality & $69.5 \pm 12$. & $72 \pm 11$ & $<0.01^{*}$ \\
\hline Physical well-being & $73.5 \pm 16.9$ & $79 \pm 19.9$ & 0.208 \\
\hline School functioning & $62 \pm 17.8$ & $74 \pm 14.8$ & $<0.01^{*}$ \\
\hline Self-esteem & $58.7 \pm 22$ & $72.5 \pm 22.8$ & $0.011^{*}$ \\
\hline Emotional well-being & $70.9 \pm 21.6$ & $76.1 \pm 14.7$ & 0.224 \\
\hline Social functioning & $73.7 \pm 22.1$ & $81.2 \pm 14.9$ & 0.087 \\
\hline Family functioning & $76.6 \pm 15.8$ & $78.6 \pm 14.9$ & 0.579 \\
\hline
\end{tabular}

${ }^{\star} p<0.05$ them had morning and $17.5 \%(n=7)$ of them had evening chronotype. In the control group, $14.7 \%(n=5)$ of them had morning and $20.6 \%$ ( $n=7)$ of them had evening chronotype. There were no significant differences in the scoring of the morningness-eveningness scale and type of chronotype among the study and control groups $(p>0.05)$. In addition to this, there were no significant differences in the chronotype and morningevening scale scores between male participants of the study and control groups and female participants of the study and control groups $(p>0.05)$. Participants of the study group had significantly shorter sleep duration than the control group (study group $8.9 \pm 0.9$, control group $9.7 \pm 1, t=3.197, p<0.01$ ).

In some subgroups of quality of life scores, there were statistically significant differences between the study and control groups. The subgroups with statistical significance were as follows: total quality of life scores (study group $69.5 \pm 12.5$, control group $77 \pm 11, \mathrm{t}=2.713, p<0.01$ ), self-esteem scores (study group $58.7 \pm 22$, control group $72.5 \pm 22.8, t=2.612, p=0.011$ ), and school functioning scores (study group $62.5 \pm 17.8$, control group $74 \pm 14.8, t=3.102, p<0.01$ ). Comparison of all type life quality of the study and control groups are presented in Table I.

In the study group, the prevalence of having any psychiatric disorders and any subthreshold psychiatric disorders were higher compared to the control group. For psychopathology: study group $-40.4 \%(n=17)$, control group - $11.4 \%(n=4)$, $X^{2}=14.280, p<0.01$. For subthreshold psychiatric disorder: study group $-14.3 \%(n=6)$, control group $-2.9 \%(n=1)$, $X^{2}=11.532, p<0.01$ ). In the study group, 11 participants were diagnosed with anxiety disorder, eight participants were diagnosed with eating disorder, two participants were diagnosed with depressive disorder, two participants were diagnosed with attention deficit hyperactivity disorder, and two participants were diagnosed with opposite defiant disorder. On the other hand, two participants were diagnosed with anxiety disorder, two participants were diagnosed with depressive disorder, and one participant was diagnosed with attention deficit hyperactivity disorder in the control group. In the study group, five participants were diagnosed with subthreshold anxiety disorder, one participant was diagnosed with subthreshold eating disorder, and one participant was diagnosed with subthreshold conduct disorder. On the other hand, one participant was diagnosed with subthreshold obsessive-compulsive disorder. When the study group were examined in terms of comorbid psychiatric disorders, $64.7 \%$ of participants in the study group had more than one comorbid psychopathology. Participants of the study group, who had comorbid at least one psychiatric disorders, had significantly low scores of total quality of life, school functioning, and self-esteem than the study group without comorbid psychiatric disorders and participants of the control group $(F=4,575, p=0.014 ; F=3.539, p=0.035$; and $F=5.886$, $p<0.01$, respectively).

In the study group, the number of comorbid psychopathologies was negatively correlated with sleep duration $(r=-532$, $p=0.028)$, and positively correlated with age $(r=553$, $p=0.021$ ). When the study group were divided into two subgroups, as having only one comorbid psychiatric disorder and 
having more than one comorbid psychiatric disorder, statistically significant differences were seen in terms of age $(9.5 \pm 2.5$, $12.2 \pm 2.3$, respectively, $t=-2.260, p=0.039$ ) sleep duration $(9.8 \pm 0.9,8.8 \pm 1$, respectively, $t=2.163, p=0.047)$, and type of chronotype (morning chronotype $50 \%[n=3], 0 \%[n=0]$, evening chronotype $16.7 \%[n=1], 27.3 \%[n=3]$, respectively, $\left.X^{2}=6.710, p=0.045\right)$. However, when we used forward logistic regression analysis to examine the independent risk factors of having more than one comorbid psychopathology, age, type of chronotype, and sleep duration lost their meaningfulness. There were negative correlations between age and total life quality, social functioning, and school functioning $(r=-406, p<0.01$; $r=-634, p<0.01$; and $r=-529, p<0.01$, respectively). There was no statistically significant relationship between having at least one psychiatric disorder and the scoring of the morningness-eveningness scale, type of chronotype, and sleep duration in the study group $(p>0.05)$. Similarly, there was no significant relationship between all quality of life scores and sleep duration, scoring of morningness-eveningness scale, and type of chronotype in the study group $(p>0.05)$.

In addition, when we used forward logistic regression analysis to examine the independent risk factors of becoming obese, the type of chronotype, the scoring of morningness-eveningness scale, and having at least one psychiatric disorder were not significant - only sleep duration was an independent risk factor for becoming obese (odds ratio $=5.023, p<0.01$ ) Moreover, when hierarchical regression analysis was performed on the number of comorbid psychiatric disorders, the duration of sleep was found to have a significant effect on the number of comorbid psychiatric disorders independently of the morning-evening scale score $(\beta=-671, p=0.047)$.

\section{Discussion}

To our best knowledge, this is the first study to investigate all types of psychiatric disorder, sleep duration, quality of life, and chronotype together in child and adolescent age groups who were diagnosed with CO. Previous studies have shown that there is a relationship between chronotype and developing obesity. Most of these studies have reported that having the evening chronotype may increase the obesity risk, and there was also a relationship between an unhealthy eating style and having evening chronotype (characterised by eating late). However, many of these studies belong to the literature about adults. In contrast to these findings, we did not find any significant difference in time of day preference between the study and control groups. One of the main reasons for not finding a difference between the two groups may be the age range of the participants. While genetic factors are more effective in the development of $\mathrm{CO}$, in contrast to childhood, disordered eating attitudes are more effective in the development of obesity in adulthood. In contrast to adulthood eating attitudes, childhood eating attitudes are determined by their parents (parental monitoring). It is emphasised that there is a relationship between chronotype and disordered eating attitudes [29-34]. In other words, genetic factors may have been more dominant in the development of obesity in the study group, instead of disordered eating attitudes due to having the evening chronotype. The other possible reason for not finding a difference in terms of chronotype between the study and control group may be the exclusion of individuals with a chronic disease such as diabetes due to the effects of the confounders.

In the literature, it has been emphasised that there is a negative correlation between the duration of sleep and the incidence of obesity, and that the shortening of sleep duration is becoming more common among children and adolescents [35, 36]. Also, recent studies have indicated that restricted sleep duration may lead to the development of obesity [37]. In parallel with these studies, we found that the sleep duration of participants with obesity was significantly shorter than those without obesity. The association of chronic short sleep duration with increased adiposity was considered as a possible cause of this relationship between restricted sleep duration and obesity [38].

In the present study, there were significant differences in the quality of life between the two groups. Similar to our study, it was reported that children with obesity had a lower healthrelated quality of life and self-esteem than their normal-weight peers [39-41]. Moreover, it was emphasised that obesity can adversely affect the school functioning of children and adolescents in various ways (such as being stigmatised by their classmates and exposure to teasing and bullying) [42]. On the other hand, Simon et al. stated no significant differences in the quality of life score between children with and without obesity [43]. However, this study was conducted in preschool-age children, so the reason for no differences could be the age range of this study. In our study, it was found that the quality of life deteriorated with age.

The prevalence of psychiatric disorders as well as subthreshold psychiatric disorders was higher in the study group in this study. These results were in concordance with previous findings, which showed that there is evidence of a higher risk of emerging psychiatric disorders and symptoms in children and adolescents with obesity than in normal-weight peers [8, 44]. In the study group, common psychiatric disorders were eating and anxiety disorders. In many studies, similar to our study, it has been reported that anxiety and eating disorders are common in children and adolescents with obesity [45-47]. In one study, it was emphasised that comorbidity with axis I/II disorders was associated with lower quality of life score [48]. When all participants were divided into three groups, it was detected that the study group with comorbid psychiatric disorders had the lowest scores of total quality of life, school functioning, and self-esteem than the study group without comorbid psychiatric disorders and participants of the control group.

Participants with evening chronotype in the study group had significantly more than one comorbid psychiatric disorders. In addition to this, shortening of sleep duration was significantly associated with having more than one psychiatric disorder, and also showed a significant correlation with increasing psychiatric disorders. However, as a result of further analyses, only the correlation between the number of psychiatric disorders and 
sleep duration remained significant within the meaningful relationships given above. Also, sleep duration was found to be an independent risk factor for becoming obese in this study. In summary, there was a strong relationship between sleep duration, developing obesity, and having a greater number of psychopathologies. In another study, sleep duration was found to be related to obesity independently of several sleep disorders [49]. The close relationship between sleep habits, obesity, and psychopathologies has been suggested to arise from possible common mechanisms between them [50].

The results of this study should be interpreted in light of various limitations. The sample size of our study was quite small, and the method was cross-sectional. In particular, longitudinal studies and larger populations are needed to demonstrate the causal relationship. Moreover, the preference of parent-reporting rather than high-sensitivity tools such as sleep data actigraphy limited the interpretation of the data. Another possible limitation of our study was the lack of assessment of

\section{References}

1. Ebbeling CB, Pawlak DB, Ludwig DS. Childhood obesity: publichealth crisis, common sense cure. Lancet 2002; 360: 473-482. doi: 10.1016/S0140-6736(02)09678-2

2. Ogden CL, Carroll MD, Kit BK, Flegal KM. Prevalence of obesity and trends in body mass index among US children and adolescents, 1999-2010. JAMA 2012; 307: 483-490. doi: 10.1001/ jama.2012.40

3. Karki A, Shrestha A, Subedi N. Prevalence and associated factors of childhood overweight/obesity among primary school children in urban Nepal. BMC Public Health 2019; 19: 1055. doi: 10.1186/ s12889-019-7406-9

4. Yılmaz M, Kundakçı GA, Dereli F, et al. İlköğretim Öğrencilerinde Yaş ve Cinsiyete Göre Obezite ve İlişkili Özellikler Obezite ve İlişkili Faktörler. Güncel Pediatri 2019; 17: 127-140.

5. Thorpe KE, Florence CS, Howard DH, Joski P. The impact of obesity on rising medical spending. Health Aff (Millwood) 2004; Suppl Web Exclusives: W4-480-6. doi: 10.1377/hlthaff.w4.480

6. Dietz WH, Robinson TN. Clinical practice. Overweight children and adolescents. N Engl J Med 2005; 352: 2100-2109. doi: 10.1056/ NEJMcp043052

7. Cortese S, Moreira-Maia CR, St Fleur D, et al. Association Between ADHD and Obesity: A Systematic Review and Meta-Analysis. Am J Psychiatry 2016; 173: 34-43. doi: 10.1176/appi.ajp.2015.15020266

8. Erermis S, Cetin N, Tamar M, et al. Is obesity a risk factor for psychopathology among adolescents? Pediatr Int 2004; 46: 296-301. doi: 10.1111/j.1442-200x.2004.01882.x

9. Türkoğlu S, Çetin FH. The relationship between chronotype and obesity in children and adolescent with attention deficit hyperactivity disorder. Chronobiol Int 2019; 36: 1138-1147. doi: 10.1080/07420528.2019.1622131

10. Golley RK, Maher CA, Matricciani L, Olds TS. Sleep duration or bedtime? Exploring the association between sleep timing behav- lifestyle habits such as physical activity and eating behaviour, which may be confusing. Despite these limitations, our study is one of the few studies evaluating the link between obesity, psychiatric disorders, sleep duration, and circadian preference in children and adolescents using structured assessment tools for all psychiatric diagnoses.

\section{Conclusions}

This study provided an assessment of the effects of chronotype and sleep duration on quality of life and development of comorbid psychiatric disorders in $\mathrm{CO}$. Also, this study, contrary to the chronotype, provided significant evidence that sleep duration, psychiatric disorders, and obesity were associated. To fully understand the relationships between sleep duration, CO, and psychiatric disorders, studies with sufficient sample sizes that allow the evaluation of statistical significance are needed.

iour, diet and BMI in children and adolescents. Int J Obes (Lond) 2013; 37: 546-551. doi: 10.1038/ijo.2012.212

11. Cappuccio FP, Taggart FM, Kandala NB, et al. Meta-analysis of short sleep duration and obesity in children and adults. Sleep 2008; 31: 619-626. doi: 10.1093/sleep/31.5.619

12. Komada Y, Abe T, Okajima I, et al. Short sleep duration and irregular bedtime are associated with increased behavioral problems among Japanese preschool-age children. Tohoku J Exp Med 2011; 224: 127-136. doi: 10.1620/tjem.224.127

13. Yokomaku A, Misao K, Omoto F, et al. A study of the association between sleep habits and problematic behaviors in preschool children. Chronobiol Int 2008; 25: 549-564. doi: 10.1080/0742052080 2261705

14. Buxton OM, Cain SW, O'Connor SP, et al. Adverse metabolic consequences in humans of prolonged sleep restriction combined with circadian disruption. Sci Transl Med 2012; 4: 129ra43. doi: 10.1126/scitranslmed.3003200

15. Reutrakul S, Hood MM, Crowley SJ, et al. Chronotype is independently associated with glycemic control in type 2 diabetes. Diabetes Care 2013; 36: 2523-2529. doi: 10.2337/dc12-2697

16. Nedeltcheva AV, Kilkus JM, Imperial J, et al. Sleep curtailment is accompanied by increased intake of calories from snacks. Am J Clin Nutr 2009; 89: 126-133. doi: 10.3945/ajcn.2008.26574

17. Chronobiology. Available at:https://www.chronobiology.com/aboutchronobiology/. 2019.

18. Selvi $Y$, Kandeger A, Boysan M, et al. The effects of individual biological rhythm differences on sleep quality, daytime sleepiness, and dissociative experiences. Psychiatry Res 2017; 256: 243-248. doi: 10.1016/j.psychres.2017.06.059

19. Psychiatry TAoCaA. Turkish Association of Child and Adolescent Psychiatry. 2019.

20. Garaulet M, Madrid JA. Chronobiological aspects of nutrition, metabolic syndrome and obesity. Adv Drug Deliv Rev 2010; 62 : 967-978. doi: 10.1016/j.addr.2010.05.005 
21. Cole TJ, Lobstein T. Extended international (IOTF) body mass index cut-offs for thinness, overweight and obesity. Pediatr Obes 2012; 7 : 284-294. doi: 10.1111/j.2047-6310.2012.00064.x

22. Goodman R, Ford T, Richards H, et al. The Development and WellBeing Assessment: description and initial validation of an integrated assessment of child and adolescent psychopathology. J Child Psychol Psychiatry 2000; 41: 645-655.

23. Dursun OB, Guvenir T, Aras S, et al. A new diagnostic approach for Turkish speaking populations DAWBA Turkish Version. Epidemiol Psychiatr Sci 2013; 22: 275-282. doi: 10.1017/S2045796012000479

24. Helmchen H, Linden M. Subthreshold disorders in psychiatry: clinical reality, methodological artifact, and the double-threshold problem. Compr Psychiatry 2000; 41 (2 Suppl 1): 1-7. doi: 10.1016/ s0010-440x(00)80001-2

25. Werner H, Lebourgeois MK, Geiger A, Jenni OG. Assessment of chronotype in four- to eleven-year-old children: reliability and validity of the Children's Chronotype Questionnaire (CCTQ). Chronobiol Int 2009; 26: 992-1014. doi: 10.1080/07420520903044505

26. Dursun OB, Ogutlu H, Esin IS. Turkish Validation and Adaptation of Children's Chronotype Questionnaire (CCTQ). Eurasian J Med 2015; 47: 56-61. doi: 10.5152/eajm.2014.0061

27. Ravens-Sieberer $U$, Bullinger M. Assessing health-related quality of life in chronically ill children with the German KINDL: first psychometric and content analytical results. Qual Life Res 1998; 7: 399-407. doi: 10.1023/a:1008853819715

28. Eser E, Yüksel H, Baydur H, et al. Cocuklar için genel amaçli sağlikla ilgili yaşam kalitesi ölçeği (Kid-KINDL) Türkçe sürümünün psikometrik özellikleri. Turk Psikiyatri Derg 2008; 19: 409-417.

29. Martinson LE, Esposito-Smythers C, Blalock DV. The effect of parental monitoring on trajectories of disordered eating attitudes and behaviors among adolescents: An individual growth curve analysis. Appetite 2016; 107: 180-187. doi: 10.1016/j.appet.2016.07.035

30. Sridhar GR, Sanjana NS. Sleep, circadian dysrhythmia, obesity and diabetes. World J Diabetes 2016; 7: 515-522. doi: 10.4239/wjd. v7.i19.515

31. Kandeger A, Egilmez U, Sayin AA, Selvi Y. The relationship between night eating symptoms and disordered eating attitudes via insomnia and chronotype differences. Psychiatry Res 2018; 268: 354-357. doi: 10.1016/j.psychres.2018.08.003

32. Ruiz-Lozano T, Vidal J, de Hollanda A, et al. Evening chronotype associates with obesity in severely obese subjects: interaction with CLOCK 3111T/C. Int J Obes (Lond) 2016; 40: 1550-1557. doi: 10.1038/ijo.2016.116

33. Kaur Y, de Souza RJ, Gibson WT, Meyre D. A systematic review of genetic syndromes with obesity. Obes Rev 2017; 18: 603-634. doi: 10.1111/obr.12531

34. Valerio G, Maffeis C, Saggese G, et al. Diagnosis, treatment and prevention of pediatric obesity: consensus position statement of the Italian Society for Pediatric Endocrinology and Diabetology and the Italian Society of Pediatrics. Ital J Pediatr 2018; 44: 88. doi: 10.1186/s13052-018-0525-6

35. Nam GE, Han K, Kim DH, et al. Sleep duration is associated with body fat and muscle mass and waist-to-height ratio beyond con- ventional obesity parameters in Korean adolescent boys. J Sleep Res 2017; 26: 444-452. doi: 10.1111/jsr.12502

36. Flint J, Kothare SV, Zihlif M, et al. Association between inadequate sleep and insulin resistance in obese children. J Pediatr 2007; 150 364-369. doi: 10.1016/j.jpeds.2006.08.063

37. Sluggett L, Wagner SL, Harris RL. Sleep Duration and Obesity in Children and Adolescents. Can J Diabetes 2019; 43: 146-152. doi: 10.1016/j.jcjd.2018.06.006

38. Taveras EM, Gillman MW, Peña MM, et al. Chronic sleep curtailment and adiposity. Pediatrics 2014; 133: 1013-1022. doi: 10.1542/ peds.2013-3065

39. Schwimmer JB, Burwinkle TM, Varni JW. Health-related quality of life of severely obese children and adolescents. JAMA 2003; 289: 1813-1819. doi: 10.1001/jama.289.14.1813

40. Williams J, Wake M, Hesketh $\mathrm{K}$, et al. Health-related quality of life of overweight and obese children. JAMA 2005; 293: 70-76. doi: 10.1001/jama.293.1.70

41. Hesketh K, Wake M, Waters E. Body mass index and parentreported self-esteem in elementary school children: evidence for a causal relationship. Int J Obes Relat Metab Disord 2004; 28 : 1233-1237. doi: 10.1038/sj.ijo.0802624

42. Schvey NA, Marwitz SE, Mi SJ, et al. Weight-based teasing is associated with gain in BMI and fat mass among children and adolescents at-risk for obesity: A longitudinal study. Pediatr Obes 2019; 14: e12538. doi: 10.1111/ijpo.12538

43. Simon SL, Stark LJ. Health-Related Quality of Life in a Community Sample of Preschool-Age Children with and without Obesity. Child Health Care 2016; 45: 376-385. doi: 10.1080/02739615.2015. 1038717

44. Tubbs AS, Khader W, Fernandez F, Grandner MA. The common denominators of sleep, obesity, and psychopathology. Curr Opin Psychol 2020; 3445.

45. Chao AM, Wadden TA, Berkowitz RI. Obesity in Adolescents with Psychiatric Disorders. Curr Psychiatry Rep 2019; 21: 3. doi: 10.1007/s11920-019-0990-7

46. Elizathe LS, Arana FG, Rutsztein G. A cross-sectional model of eating disorders in Argentinean overweight and obese children. Eating Weight Disorders-Studies on Anorexia, Bulimia Obesity 2018; 23: 125-132.

47. Amiri S, Behnezhad S. Obesity and anxiety symptoms: a systematic review and meta-analysis. Neuropsychiatr 2019; 33: 72-89. doi: 10.1007/s40211-019-0302-9

48. Carpiniello B, Pinna F, Pillai G, et al. Psychiatric comorbidity and quality of life in obese patients. Results from a case-control study Int J Psychiatry Med 2009; 39: 63-78. doi: 10.2190/PM.39.1.e

49. Solmi M, Köhler CA, Stubbs B, et al. Environmental risk factors and nonpharmacological and nonsurgical interventions for obesity: An umbrella review of meta-analyses of cohort studies and randomized controlled trials. Eur J Clin Invest 2018; 48: e12982. doi: 10.1111/eci.12982

50. Tubbs AS, Khader W, Fernandez F, Grandner MA. The common denominators of sleep, obesity, and psychopathology. Curr Opin Psychol 2020; 34: 84-88. doi: 10.1016/j.copsyc.2019.11.003 